\title{
High satisfaction ratings in an orthogeriatric ward: A cross-sectional survey
}

\author{
Charlotte Abrahamsen ${ }^{* 1,2}$, Eva Draborg ${ }^{2}$, Birgitte Nørgaard ${ }^{2}$ \\ ${ }^{1}$ Department of Orthopaedic Surgery, Kolding Hospital, Kolding, Denmark \\ ${ }^{2}$ Department of Public Health, University of Southern Denmark, Odense, Denmark
}

Received: February 2, 2017

Accepted: March 14, 2017

Online Published: March 23, 2017

DOI: $10.5430 /$ jnep.v7n9p13

URL: https://doi.org/10.5430/jnep.v7n9p13

\begin{abstract}
Patients' experiences and satisfaction should be incorporated when quality of healthcare is assessed as patients offer key insights into the quality of care and treatment. Over a period of 12 months, 236 elderly patients (+65 years) with hip fracture, vertebral fracture or other appendicular fractures were questioned concerning their satisfaction and experience of admission to an orthogeriatric unit. Research nurses questioned the patients using an electronic questionnaire. Our survey documents a high level of satisfaction with the clinical elements of orthogeriatric care. On average $80 \%$ of the patients felt respected by professionals all or most of the time; $72 \%$ felt confident at discharge. Equally large groups preferred very much, little or no involvement; and $74 \%$ of the patients preferred family involvement. In total, $64 \%$ felt the extent of their own involvement in care and treatment had been appropriate, while $52 \%$ felt this was the case for family involvement. Some patients reported no experience of training or ward rounds taking place, no opportunity to speak with a physician when needed, and receiving no information about waiting time. Our results contribute to the limited knowledge concerning the satisfaction and experiences of orthogeriatric in-hospital patients.
\end{abstract}

Key Words: Orthogeriatric care, Patient satisfaction, Patient reported experience measurement, Survey

\section{INTRODUCTION}

Patients' experiences and satisfaction should be incorporated when quality of healthcare is assessed. ${ }^{[1]}$ Patients' unique experiences enable them to offer key insights into the quality of care and treatment, specifically concerning the way treatment, processes or interactions are perceived. ${ }^{[2]}$

Research shows that patient satisfaction present a highly optimistic picture, whereas detailed questions about specific aspects of patient experiences are likely to be more useful for monitoring quality in care. ${ }^{[3]}$ Questions assessing patient experience are directed more towards a particular service, hospital episode or clinician and respondents are asked to report whether or not certain processes or events occurred. ${ }^{[4]}$
Generally recognised, the concept of patient satisfaction has an array of interpretations and lacks clarity. Donabedian ${ }^{[5]}$ argue that satisfaction is based on personal relationships within healthcare systems and healthcare outcomes. Thus, themes about satisfaction with treatment provided, interprofessional processes including respect, information received and experienced participation are relevant. ${ }^{[6]}$

Furthermore, there is a growing body of qualitative and quantitative studies on elderly patients' preferences in relation to different aspects of care experience. Elderly hospitalised patients wish to be involved in the discharge planning. ${ }^{[7]}$ However their preferences and capacity for participation in hospital admission and discharge seem to vary consid-

\footnotetext{
*Correspondence: Charlotte Abrahamsen; Email: charlotte.s.abrahamsen@ rsyd.dk; Address: Department of Orthopaedic Surgery, Kolding Hospital, 6000 Kolding, Denmark.
}

Published by Sciedu Press 
erably $^{[8]}$ and to some extend frail elderly patients think of participation as good communication and information and not necessarily as participating in decisions on medical treatments. ${ }^{[9]}$ Moreover, relatives appear to be an important advocate to the elderly patients in providing practical support both during admission and discharge. ${ }^{[8]}$

This paper is, to our knowledge, the first to report a study of orthogeriatric care from a patient perspective. The aim was to investigate patient satisfaction and patient-reported experiences in an orthogeriatric unit.

\section{METhOD}

\subsection{Design}

The study was designed as a cross-sectional questionnaire survey. Data were collected between September 2014 and September 2015 in a regional hospital with no co-payment serving a mixed rural and urban district in Denmark.

\subsection{Respondents and data collection}

The study was carried out in an orthogeriatric unit in which all acute patients of 65 years or older with fragility fracture were admitted.

Fragility fractures were defined as fractures occurring after minimal trauma, such as falling from a standing height or less, or after no identifiable trauma. ${ }^{[10]}$

All patients admitted to this orthogeriatric unit were assessed for eligibility to our study by a research nurse prior to discharge. Patients were excluded on the following grounds: surgery elsewhere; transferred to another department or hospital after surgery; discharged during weekends, holidays or within 24 hours of admission; no command of Danish; or death during the data collection period. Also patients suffering from mental or physical conditions precluding meaningful response were excluded.

Patients were contacted on the day of discharge or the day before, yet no contact during weekends and holidays. Due to the age and frailty of the population, research nurses questioned the patients using an electronic questionnaire accessible from an iPad device. ${ }^{[11]}$ The questioning was performed by four experienced research nurses who had received training to ensure uniformity in procedure, approach, and motivation of the patients. To avoid bias they were asked to dress in their own clothes and introduce themselves as "interviewers".

Patient data regarding fracture type, age, gender, time to surgery (hours) and length of stay (hours) were furthermore obtained from the hospital's patient administration system.

\subsection{Orthogeriatric care}

At the emergency room all acutely admitted patients were examined by an orthopaedic surgeon and transferred to the orthogeriatric unit for care and treatment.

The orthogeriatric unit was staffed with an interprofessional team of orthopaedic surgeons, geriatric specialists, nurses, nursing assistants, physiotherapists, occupational therapists and dietitians collaborating on the treatment of elderly patients with a fragility fracture in addition to chronic or other diseases and with functional disabilities.

Each weekday, an interprofessional conference was conducted in which treatment, training, nursing care and discharge planning for each patient was discussed. The patients were assessed in ward rounds by an orthopaedic surgeon or a geriatric specialist. Nurses and nursing assistants were responsible for nursing and the collaboration with relatives and municipalities. All patients received daily physiotherapy training, while those with severe functional challenges were offered training in daily living activities by occupational therapists. Where relevant, plans for early discharge were discussed with the family. For all patients who had previously received municipal home care, a discharge report was sent. If major changes were needed, video conferences were conducted.

\subsection{Questionnaire}

Our questionnaire was inspired by both the generic sevenitem Short Assessment of Patient Satisfaction Survey (SAPS) developed and validated by Hawthorne et al. ${ }^{[6]}$ and a Danish satisfaction survey developed and validated for orthopaedic patients. ${ }^{[12]}$ The SAPS scale is based on a theoretical model covering all dimensions known to contribute to patient satisfaction. ${ }^{[6]}$ The original Danish questionnaire covers the subthemes availability, information, medical ability, nursing ability, planning of care path, and physical environment. It was developed for and validated in orthopaedic patients above the age of 18. ${ }^{[12]}$ Ten items from this questionnaire were added to the SAPS questions. Eight questions concerning therapists' competence, interprofessional collaboration, patient and family involvement and confidence at discharge were added to reflect the interprofessional orthogeriatric model and the frailty of the patient population. We furthermore asked them about training specified in details as: rise and sit on the bedside, get out of bed, gait training, training in the bathroom, workout on stairs and group exercise.

The 25-item questionnaire was face validated and pilot tested in a three-step procedure involving 15 representative patients. This prompted the removal of six redundant items and furthermore accommodated the patients' wish for a less compre- 
hensive questionnaire. Minor adjustments were subsequently made to improve comprehensibility and relevance, thus a 19-item questionnaire was used in the study.

The relevance of each question was furthermore assessed by an expert group of eight professionals (therapists, physicians and nurses) working in the orthogeriatric unit. On a 1-4 point scale, 1 indicated items deemed irrelevant, 4 highly relevant items. The mean scores for the 19 items were 3.1-4.0 (see Table 1).

Table 1. Assessment of item relevance (Score 1-4; 1 indicating item is irrelevant and 4 highly relevant)

\begin{tabular}{|c|c|c|c|c|c|c|c|c|c|c|}
\hline \multirow{2}{*}{$\begin{array}{l}\text { Item } \\
\text { number }\end{array}$} & \multicolumn{8}{|c|}{ Healthcare professionals } & \multirow{2}{*}{$\begin{array}{l}\text { Number of profe- } \\
\text { ssionals scoring } \geq 3\end{array}$} & \multirow{2}{*}{ Mean } \\
\hline & $\mathbf{A}$ & B & C & D & $\mathbf{E}$ & $\mathbf{F}$ & G & $\mathbf{H}$ & & \\
\hline 1 & 4 & 4 & 4 & 3 & 1 & 3 & 4 & 2 & 6 & 3.1 \\
\hline 2 & 4 & 4 & 4 & 4 & 4 & 4 & 4 & 4 & 8 & 4 \\
\hline 3 & 4 & 3 & 4 & 4 & 4 & 4 & 4 & 4 & 8 & 3.9 \\
\hline 4 & 4 & 4 & 4 & 4 & 4 & 1 & 4 & 4 & 7 & 3.6 \\
\hline 5 & 4 & 3 & 4 & 3 & 4 & 3 & 4 & 3 & 8 & 3.5 \\
\hline 6 & 4 & 4 & 4 & 4 & 4 & 3 & 4 & 3 & 8 & 3.8 \\
\hline 7 & 3 & 3 & 4 & 4 & 4 & 3 & 4 & 3 & 8 & 3.5 \\
\hline 8 & 4 & 3 & 4 & 4 & 4 & 3 & 4 & 4 & 8 & 3.8 \\
\hline 9 & 3 & 3 & 4 & 4 & 4 & 3 & 4 & 3 & 8 & 3.5 \\
\hline 10 & 4 & 2 & 4 & 4 & 4 & 4 & 4 & 4 & 7 & 3.8 \\
\hline 11 & 3 & 4 & 4 & 4 & 1 & 4 & 4 & 3 & 7 & 3.4 \\
\hline 12 & 4 & 3 & 4 & 3 & 1 & 4 & 4 & 4 & 7 & 3.4 \\
\hline 13 & 4 & 4 & 4 & 3 & 3 & 4 & 4 & 2 & 7 & 3.5 \\
\hline 14 & 4 & 4 & 4 & 3 & 2 & 4 & 4 & 2 & 6 & 3.4 \\
\hline 15 & 4 & 4 & 4 & 3 & 4 & 4 & 4 & 3 & 8 & 3.8 \\
\hline 16 & 4 & 4 & 4 & 3 & 4 & 4 & 4 & 3 & 8 & 3.8 \\
\hline 17 & 4 & 4 & 4 & 3 & 4 & 4 & 4 & 3 & 8 & 3.8 \\
\hline 18 & 4 & 4 & 4 & 3 & 4 & 4 & 4 & 4 & 8 & 3.9 \\
\hline 19 & 4 & 4 & 4 & 3 & 4 & - & 4 & 4 & $7^{*}$ & $3.9 *$ \\
\hline
\end{tabular}

*1 missing answer

We furthermore evaluated the consistency of our questionnaire using Cronbach's alpha; the full-scale alpha was 0.7 ; when analysed case-wise, the alpha ranged between 0.68 and 0.71 .

Response options concerning satisfaction (9 items) were presented on a 4-point Likert scale with the options very satisfied, satisfied, dissatisfied, very dissatisfied, don't know and (where relevant) an option to indicate that the respondent had no experience of the issue. Eliciting responses on perceived respect, the options were presented on a 5-point Likert scale with the options all the time, most of the time, half the time, some of the time, at no time and don't know. To questions concerning preferences for the degree of involvement, the response options were yes, very much, yes, to some extent, no, not at all, don't know or not relevant. The perceived degree of involvement was indicated by either too much, appropriate, too little, don't know or, for questions on family involvement not relevant. Finally, the response options for question on confidence at discharge were very confident, confident, unconfident or very unconfident. All 19 questions required a response.

\subsection{Ethics}

Oral and written information of the survey was given to all participants just before the questioning. According to Danish law, response to the questions was considered indication of voluntary consent to participation. Patient information included information on anonymity, confidentiality and the possibility to withdraw at any time without consequences.

The study was approved by the Danish Data Protection Agency (2008-58-0035), the Danish Health and Medicines Authority (3-3013-612/1); no approval from the Regional Scientific Ethical Committees of Southern Denmark was required. 


\subsection{Analysis}

The questionnaire data were merged with data from the administration system using the patients' Danish social security number. Only matching data from both sources were included in the final analyses.

Responses concerning satisfaction were dichotomized, collapsing very satisfied and satisfied and dissatisfied and very dissatisfied into two groups. Responses regarding perceived respect were coded as either all or most of the time or nearly half the time or less. Responses regarding discharge were coded as either positive responses or negative responses.

Questionnaire data and categorical patient characteristics were expressed as proportions and analysed by, chi-squared test. Numeric patient characteristics were expressed in means and compared using Kruskal-Wallis tests with $p<.05$ as significance level.
Furthermore, confidence at discharge was explored in relation to age and length of stay by using Student's $t$-test and in relation to gender by using chi-squared test.

In order to test the internal consistency of our questionnaire we performed a full scale Cronbach's Alpha.

All analyses were performed using Stata 13 software (StataCorp. 2013. Stata Statistical Software: Release 13. College Station, TX: StataCorp. LP).

\section{RESULTS}

Of the 306 elderly patients included in the study, 236 completed the questionnaire, equivalent to a response rate of $77.1 \%$ (see Figure 1).

Mean age 78.8 years (SD 8.3); mean length of stay 157.2 hours (SD 88.5); mean time to surgery 29.4 hours (28.3); females $78.0 \%$ (see Table 2).

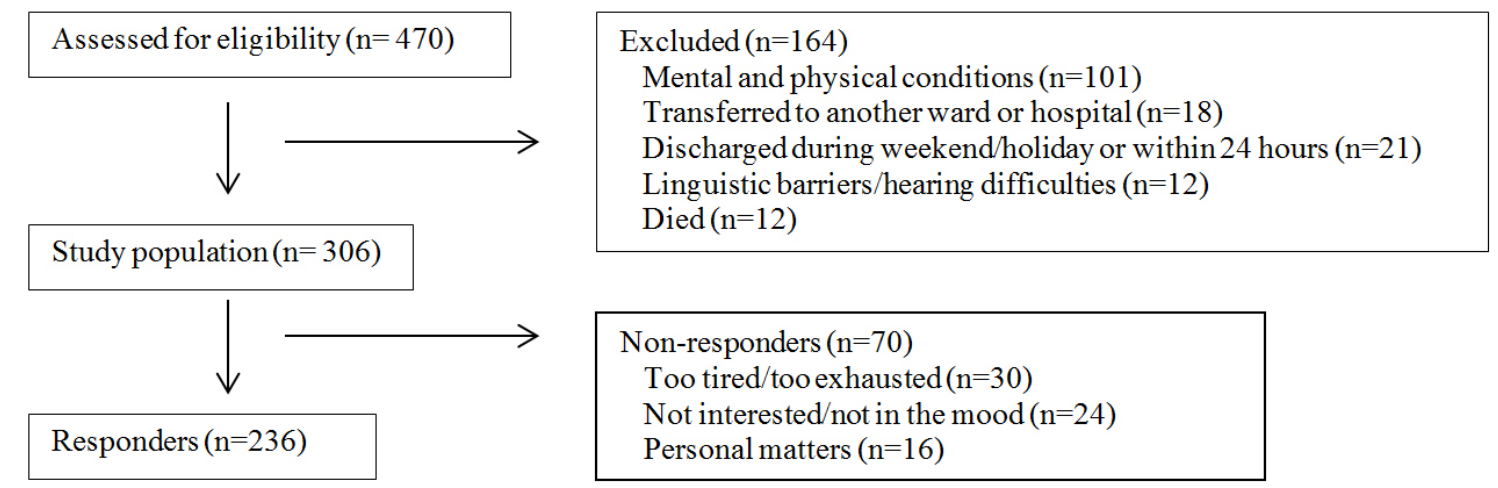

Figure 1. Flowchart

Table 2. Respondent demographics

\begin{tabular}{lllll}
\hline & $\begin{array}{l}\text { Hip } \\
\text { fracture }\end{array}$ & $\begin{array}{l}\text { Vertebral } \\
\text { fracture }\end{array}$ & $\begin{array}{l}\text { Other fragility } \\
\text { fractures }\end{array}$ & Total \\
\hline Participants (\%) & $120(50.9)$ & $26(11.0)$ & $90(38.1)$ & $236(100)$ \\
Female (\%) & $84(70.0)$ & $23(88.5)$ & $77(85.6)$ & $184(78.0)^{\wedge}$ \\
Mean age (years, SD) & $80.2(8.3)$ & $80.1(7.7)$ & $76.6(7.9)$ & $78.8(8.3)^{\wedge}$ \\
Mean length of stay (hours, SD) & $190.8(76.3)$ & $140.7(66.7)$ & $117.3(92.0)$ & $157.2(88.5)^{\wedge}$ \\
Mean time to surgery (hours, SD) & $23.6(21.4)$ & $29.0^{*}$ & $37.7(34.6)$ & $29.4(28.3)^{* * \wedge}$ \\
\hline
\end{tabular}

$* 1$ of whom underwent surgery; thus $\mathrm{SD}=0 . * * 195$ of whom underwent surgery. $\wedge$ significant difference between patient groups $(<.01)$

\subsection{Waiting times, information and staff accessibility (Q1, Q2, Q4, Q5 and Q6)}

The questions concerning waiting time from admission to surgery were irrelevant for those $14.4 \%$ of the patients who did not require surgery; $22.8 \%$ experienced no waiting time, while $6.6 \%$ reported that no information on waiting time had been given. In total, $69.5 \%$ indicated satisfaction with waiting times from admission to surgery; 53\% satisfaction with information about waiting time (see Table 3 ). We found no correlations between satisfaction with waiting time and time to surgery.

Of all respondents, no less than $30.9 \%$ stated they had no experience of ward rounds, while $58.1 \%$ expressed satisfaction with the ward rounds (see Table 3 ). 
Table 3. Patient experience and patient satisfaction $(n=236)$

\begin{tabular}{|c|c|c|c|c|c|}
\hline Waiting time, information and staff accessibility & $\begin{array}{l}\text { Very satisfied } \\
\text { or satisfied }\end{array}$ & $\begin{array}{l}\text { Dissatisfied or } \\
\text { very dissatisfied }\end{array}$ & & $\begin{array}{l}\text { Don't } \\
\text { know }\end{array}$ & $\begin{array}{l}\text { No } \\
\text { experience }\end{array}$ \\
\hline $\begin{array}{l}\text { How satisfied were you with the waiting time from } \\
\text { admission to surgery? }\end{array}$ & $164(69.5)$ & $28(11.9)$ & & $10(4.2)$ & $34(14.4)^{*}$ \\
\hline $\begin{array}{l}\text { How satisfied were you with information about reasons } \\
\text { for waiting time in general? }\end{array}$ & $125(53.0)$ & $26(11.0)$ & & $15(6.4)$ & $70(29.6)^{* *}$ \\
\hline How satisfied were you with ward rounds? & $137(58.1)$ & $12(5.1)$ & & $14(5.9)$ & $73(30.9)$ \\
\hline $\begin{array}{l}\text { How satisfied were you with the possibility of talking to } a \\
\text { physician when needed? }\end{array}$ & $70(29.7)$ & $11(4.7)$ & & $70(29.7)$ & $85(36.0)$ \\
\hline $\begin{array}{l}\text { How satisfied were you in general with information from } \\
\text { physicians? }\end{array}$ & $180(76.3)$ & $12(5.1)$ & & $15(6.4)$ & $29(12.2)$ \\
\hline Treatment, care and training & $\begin{array}{l}\text { Very satisfied } \\
\text { or satisfied }\end{array}$ & $\begin{array}{l}\text { Dissatisfied or } \\
\text { very dissatisfied }\end{array}$ & & $\begin{array}{l}\text { Don't } \\
\text { know }\end{array}$ & $\begin{array}{l}\text { No } \\
\text { experience }\end{array}$ \\
\hline How satisfied were you with treatment by physicians? & $216(91.5)$ & $7(3.0)$ & & $9(3.8)$ & $4(1.7)$ \\
\hline How satisfied were you with nursing and care? & $217(91.9)$ & $16(6.8)$ & & $3(1.3)$ & \\
\hline How satisfied were you with training? & $173(73.3)$ & $9(3.8)$ & & $11(4.7)$ & $43(18.2)$ \\
\hline $\begin{array}{l}\text { How satisfied were you with staff collaboration on your } \\
\text { treatment? }\end{array}$ & 165 (69.9) & $11(4.7)$ & & $60(25.4)$ & \\
\hline Respect & $\begin{array}{l}\text { All or most } \\
\text { of the time }\end{array}$ & $\begin{array}{l}\text { Nearly half the } \\
\text { time or less }\end{array}$ & & $\begin{array}{l}\text { Don't } \\
\text { know }\end{array}$ & $\begin{array}{l}\text { Not } \\
\text { relevant }\end{array}$ \\
\hline $\begin{array}{l}\text { How much of the time did you feel respected by the } \\
\text { physicians? }\end{array}$ & $179(75.8)$ & $15(6.4)$ & & $42(17.8)$ & \\
\hline $\begin{array}{l}\text { How much of the time did you feel respected by the } \\
\text { nursing staff? }\end{array}$ & $209(88.6)$ & $24(10.2)$ & & $3(1.2)$ & \\
\hline $\begin{array}{l}\text { How much of the time did you feel respected by the } \\
\text { therapists? }\end{array}$ & $175(74.1)$ & $12(5.1)$ & & $49(20.8)$ & \\
\hline Patient and family preference for involvement & $\begin{array}{l}\text { Yes, } \\
\text { very much }\end{array}$ & $\begin{array}{l}\text { Yes, } \\
\text { to some extent }\end{array}$ & $\begin{array}{l}\text { No, } \\
\text { not at all }\end{array}$ & $\begin{array}{l}\text { Don't } \\
\text { know }\end{array}$ & $\begin{array}{l}\text { Not } \\
\text { relevant }\end{array}$ \\
\hline Do you wish to be involved regarding treatment options? & $75(31.8)$ & $50(21.2)$ & $81(34.3)$ & $30(12.7)$ & \\
\hline $\begin{array}{l}\text { Do you think that your family should be involved during } \\
\text { your admission? }\end{array}$ & $111(47.0)$ & $64(27.1)$ & $17(7.2)$ & $5(2.1)$ & $39(16.5)$ \\
\hline Perceived involvement of patient and family & Too much & Appropriately & Too little & $\begin{array}{l}\text { Don't } \\
\text { know }\end{array}$ & $\begin{array}{l}\text { Not } \\
\text { relevant }\end{array}$ \\
\hline To what extent were you involved regarding treatment? & $2(0.8)$ & $150(63.6)$ & $16(6.8)$ & $68(28.8)$ & \\
\hline $\begin{array}{l}\text { To what extent was your family involved regarding care } \\
\text { and treatment? }\end{array}$ & $1(0.4)$ & $123(52.1)$ & $10(4.2)$ & $27(11.5)$ & $75(31.8)$ \\
\hline $\begin{array}{ll}17 & \begin{array}{l}\text { To what extent was your family involved regarding } \\
\text { discharge? }\end{array}\end{array}$ & $0(0)$ & $114(48.3)$ & $10(4.2)$ & $40(17.0)$ & $72(30.5)$ \\
\hline Discharge & $\begin{array}{l}\text { Very } \\
\text { confident }\end{array}$ & Confident & Unconfident & $\begin{array}{l}\text { Very } \\
\text { unconfident }\end{array}$ & \\
\hline How confident do you feel about discharge? & $64(27.1)$ & $105(44.5)$ & $49(20.8)$ & $18(7.6)$ & \\
\hline What makes you feel unconfident $(\mathrm{n}=67) ?$ & Yes & & & & \\
\hline Transportation to home & $14(20.9)$ & & & & \\
\hline Health situation & $41(61.2)$ & & & & \\
\hline Functional ability & $56(83.6)$ & & & & \\
\hline Medication & $10(14.9)$ & & & & \\
\hline Doubts about sufficient home help & $39(58.2)$ & & & & \\
\hline Practical issues & $27(40.3)$ & & & & \\
\hline
\end{tabular}

* No surgery, $* * 6.8 \%$ no information and $22.8 \%$ no waiting time in general

When asked about their satisfaction with opportunities to talk to a physician when they had needed this, $29.7 \%$ of the patients reported satisfaction, $29.7 \%$ (sic) responded don't know and $36.0 \%$ had no experience of meeting a physician when they had needed it. However, 76.3\% expressed satisfaction with the information they had received from physicians

Published by Sciedu Press

(see Table 3).

Clinical elements of orthogeriatric care: Treatment, training, care and staff collaboration. (Q3, Q 8, Q10 and Q12) Satisfaction with physicians' treatment were reported by $91.5 \%$; satisfaction with nursing and care by $91.9 \% ; 73.3 \%$ were satisfied with the training and $69.9 \%$ with the collaboration 
on their treatment. However, $18.2 \%$ of the respondents indicated that they had no experience of training; while $25.4 \%$ responded don't know when asked about staff collaboration (see Table 3).

\subsection{Respect (Q7, Q9 and Q11)}

Of all responders, $74.1 \%, 75.8 \%$ and $88.6 \%$ felt respected all or most of the time by therapists, physicians or nursing staff, respectively. The nursing staff had made $10.2 \%$ feel respected nearly half the time or less. Almost $18 \%$ and $21 \%$ expressed no opinion concerning perceived respect from physicians and therapists, respectively (see Table 3 ).

\subsection{Patient and family involvement (Q13-Q17)}

The respondents were asked about their preferences and perceptions concerning involvement in decisions on treatment. Overall, $53 \%$ of them expressed a wish for extensive or moderate involvement, $34.3 \%$ wanted no involvement, while $12.7 \%$ expressed no opinion (see Table 3 ). One hundred and fifty respondents $(63.6 \%)$ found they had been involved to an appropriate degree; $28.8 \%$ expressed no opinion. Of the first group, there were respondents expressing extensive, moderate or no involvement. Analysis of the association between the preference for high patient involvement and age by groups (65-74 years [ref]; 75-84 years; above 85 years) showed decreasing OR values with increasing age (OR 0.66; $p=.2$; OR $0.39 ; p=.008$ ) indicating that preference for high patient involvement decreased with age.

When asked about preferences regarding family involvement during their admission, 175 respondents $(74.1 \%)$ expressed a wish for extensive or moderate involvement, while $16.5 \%$ responded that the question was not relevant. Eliciting the patients' perceptions of family involvement in decisions on care and treatment options, $52.1 \%$ found that the degree of involvement had been appropriate; $31.8 \%$ indicated that the question was not relevant. Furthermore, $48.3 \%$ of the patients stated that family involvement in connection with discharge had been appropriate, while $4.2 \%$ felt the involvement had been inadequate. The question was deemed irrelevant by $30.5 \%$ (see Table 3 ).

\subsection{Discharge (Q18-Q19)}

Overall, $71.6 \%$ of the respondents felt confident about discharge, while $20.8 \%$ reported feeling unconfident and $7.6 \%$ that they felt very unconfident. Of the 67 respondents who indicated a lack of confidence, $83.6 \%$ expressed concern about their functional ability, $61.2 \%$ about their health, $58.2 \%$ about sufficient help in the home, and $40.3 \%$ about practical issues. Medication and transportation to their home was indicated as the cause of concern by $14.9 \%$ and $20.9 \%$, respectively (see Table 3 ). Fifty patients $(74.6 \%$ ) reported 2-4 reasons each for feeling unconfident at discharge, ten patients reported no more than one reason and seven reported 5-6 reasons.

Further analysis revealed no association between patients' gender and confidence at discharge. However, a comparison of patients feeling very confident or confident with patients feeling unconfident or very unconfident showed a significant difference of 2.6 years in mean age (78.1 vs. 80.7 years; $p=$ $.02)$; the lack of confidence was thus found to increase with respondents' age. The length of stay was found to correlate inversely with confidence; while the mean length of stay for patients indicating confidence was 143.9 hours, those who indicated a lack of confidence had stayed for a mean of 191.0 hours $(p<.001)$, a difference of 47.1 hours.

\subsection{Dropout analysis}

The study population covered 306 patients, of who 70 declined participation citing tiredness or lack of energy. Overall, non-responders' mean age was 79.7 years; mean length of stay was 177.0 hours; mean time to surgery was 28.6 hours; $80 \%$ were female; $45.7 \%$ had been admitted with hip fracture, $17.1 \%$ with vertebral fracture and $37.2 \%$ with other fractures. No significant differences were found when comparing the results for non-responders with those for responders (data not shown).

\section{Discussion}

Generally, the patients indicated that they were very satisfied with the clinical elements of the stay in the orthogeriatric unit (treatment, training and care), with staff accessibility, information and with waiting times when they occurred. As such high ratings in relation to patient satisfaction are frequently found, ${ }^{[13]}$ what learning can be gleaned from a survey such as this would likely come from the examination of evidence of patients' dissatisfaction and their experience that they had not received elements of care. ${ }^{[14]}$

Eighteen percent of the patients stated that they had received no training, while $29 \%, 31 \%$ and $36 \%$, respectively stated they had no experience of ward rounds, had not spoken with a physician when needed or had received no information about delays. As we do not know the underlying reasons for these findings, further qualitative studies are needed. Yet, a possible explanation for missing ward rounds could be that the ward rounds have changed over years; from a tail of professionals to a single person arriving at the patient for a brief moment. Thus, elderly patients may not recognise ward rounds as they were. Also some physicians do not introduce themselves thoroughly by name and profession or mention the specific purpose of meeting. Thus, responses to the lack of experiencing ward rounds could reflect insufficient knowl- 
edge of person or setting. To accommodate these findings, initiatives to improve patient communication and awareness on ward rounds and training can be initiated with the intention to increase patient satisfaction and experience. In total, $74 \%, 76 \%$ and $89 \%$ of the patients had felt respected all or most of the time by therapists, physicians and nursing staff, respectively.

Furthermore, 64\% felt they had been involved to an appropriate degree, with equally large groups preferring very much, little, and no involvement (don't know: 29\%). To our knowledge, no studies concerning patient involvement in elderly patients in orthopaedic surgery settings have previously been conducted. However, a meta-analysis from 2010 found that $61 \%$ of patients with a cancer diagnosis had experienced appropriate involvement in decisions on treatment; again with an equal distribution among groups. ${ }^{[15]}$ This could indicate that patient involvement in general varies and that healthcare professionals and patients need to balance expectations.

Seventy-four percent of the patients preferred involvement of family; $52 \%$ and $48 \%$ had experienced appropriate family involvement in treatment and discharge, respectively. The question was found irrelevant by $30 \%$ of the patients; indicating not having any family or not needing them to participate. Our results concerning perception of an appropriate degree of family involvement are lower than the results gained from a study conducted in five Danish emergency departments; $65.2 \%$ of the patients stated their family had been involved appropriately. ${ }^{[16]}$ The difference in appropriate family involvement experienced could be explained by the missing response category (not relevant). Yet, also here expectations need to be balanced. In the same study, $79 \%$ of the respondents stated confidence at discharge from the emergency department. ${ }^{[16]}$ This mirrors our finding of $72 \%$ feeling confident at discharge. However, the fact that we excluded patients discharged during weekends could imply a bias, as their confidence may have been lower. When the patients in our study expressed a lack of confidence, they were typically concerned about their functional ability. Concerns about health, sufficient help in the home and other practical issues were also voiced. Patients lacking confidence furthermore tended to be older and having longer admissions; this leads us to believe that our patients are among the most fragile persons living in their own home.

\section{Strengths and limitations}

Although the differences in care pathways and lengths of stay between the three diagnostic groups speak for the relevance of analysis, our sample size did not permit this.

A review examining patient satisfaction after total knee and

Published by Sciedu Press hip arthroplasty has outlined possible determinants and components affecting satisfaction. ${ }^{[17]}$ Comorbidity, disappointed expectations, pain and severity of disease were some of the determinants that had a negative effect on satisfaction. Furthermore anaesthetic and postoperative complications are relevant components. As we have no data for most of these relevant factors, we are unable to account for the possible impact on our results. Age, which is known to correlate with satisfaction, may, however, have affected our satisfaction results positively.

Of our study population, 164 patients (35\%) were not eligible for inclusion, primarily due to poor health, discharge within 24 hours, death or transfer. They were significantly older (mean 82.3 years; $p<.001$ ) than the included patients and their stays significantly shorter, (mean 135.7 hours; $p=.003$ ). Hip fracture was the most frequent cause of admission among the excluded group, with $71.3 \%$; $6.7 \%$ had suffered vertebral fractures; other fragility fractures accounted for $22 \%$. This supports our perception that we reached the fittest section of the study population. Of the 306 included patients, 236 (78.8\%) responded to the questionnaire whereas 70 declined because of tiredness, exhaustion or poor mood. Responders' and non-responders' age, time to surgery, and length of stay showed no significant differences.

In orthopaedic research, the majority of studies of patient satisfaction have concerned patients undergoing elective surgery, or they have compared two different treatments, with VAS scores being the typical outcome measure. None of the available satisfaction instruments are designed or validated for surgical practice. ${ }^{[18]}$ Although improved patient satisfaction is a major goal of orthogeriatric co-management. ${ }^{[19]}$

The 19-item questionnaire was based on two validated questionnaires, it was face validated and pilot tested and subsequently tested for content validity by experts. We found this context-relevant questionnaire sufficiently sensitive to identify anticipated nuances of satisfaction and experience. By developing a short and specific questionnaire, we sought to raise the response rate and give respondents opportunity to express dissatisfaction with specific elements of care.

Because of the frail elderly population and the wish for a high response rate, we questioned the patients using an electronic questionnaire, as it is the least burdensome method. ${ }^{[11]}$ The training of the research nurses aimed at minimizing variation in the questioning, reduce the possibility of social desirability bias and improve reliability. ${ }^{[11]}$

To achieve high response rates and cause minimal inconvenience we chose to conduct the questioning immediately before discharge. Although it is generally agreed that the 
time of administration of patient satisfaction questionnaires influences satisfaction ratings, there is no consensus on its precise effect. Yet responses obtained "on the spot" tend to be more positive than in their home after discharge. ${ }^{[14,20]}$

These findings are based on a local Danish context and culture; however the questionnaire can be recommended for use in other orthogeriatric units.

\section{Conclusion}

Our study demonstrates high patient satisfaction ratings concerning the clinical elements of the provided orthogeriatric care. The proportion of patients feeling respected and feeling confident at discharge was high. The distribution of patients according to their preferred degree of involvement (very much, little or no involvement) was even; yet, the majority of the patients preferred that their family was involved. Our findings indicate room for improvement; for example that a number of patients reported no experience of training or ward rounds, or been offered information about waiting time. Some felt a need for better access to physicians. As the experiences underlying the patients' responses are poorly understood, further in-depth exploration is relevant.

Our results add to the limited body of knowledge on patient satisfaction and patient experience of admission to orthogeriatric wards.

\section{ACKNOWLEDGEMENTS}

We are grateful for the collaboration of patients in the Department of Orthopaedic Surgery, and we wish to acknowledge the contribution of the research nurses in the Department of Medicine, at Kolding Hospital.

\section{CONFLICTS OF INTEREST DisClosure}

The authors declare that there is no conflict of interest.

\section{REFERENCES}

[1] Sitzia J, Wood N. Patient satisfaction: a review of issues and concepts Soc Sci Med. 1997; 45(12): 1829-43. https : //doi .org/10.101 6/S0277-9536(97)00128-7

[2] Beattie M, et al. Instruments to measure patient experience of healthcare quality in hospitals: a systematic review. Syst Rev. 2015; 4: 97. PMid:26202326 https://doi.org/10.1186/s13643-015-008 9-0

[3] Jenkinson C, et al. Patients' experiences and satisfaction with health care: results of a questionnaire study of specific aspects of care. Quality and Safety in Health Care. 2002; 11(4): 335-339. PMid:12468693 https://doi.org/10.1136/qhc.11.4.335

[4] Fitzpatrick CAR, Cornwell J. Measures of patients' experience in hospital: purpose, methods and uses. King's Fund London. 2009.

[5] Donabedian A. The quality of care: how can it be assessed? JAMA; 1988; 260(12): 1743-1748. PMid:3045356 https : //doi .org/10 $.1001 /$ jama. 1988.03410120089033

[6] Hawthorne G, et al. Measuring patient satisfaction with health care treatment using the Short Assessment of Patient Satisfaction measure delivered superior and robust satisfaction estimates. J Clin Epidemiol. 2014; 67(5): 527-37. PMid:24698296 https ://doi .org/10.101 6/j.jclinepi.2013.12.010

[7] Foss C, Hofoss D. Elderly persons' experiences of participation in hospital discharge process. Patient Education \& Counseling. 2011; 85(1): 68-73. PMid:20884160 https://doi.org/10.1016/j.pe c. 2010.08 .025

[8] Dyrstad DN, Laugaland KA, Storm M. An observational study of older patients' participation in hospital admission and dischargeexploring patient and next of kin perspectives. J Clin Nurs. 2015; 24(11-12): 1693-706. PMid:25727777 https ://doi .org/10.111 $1 /$ jocn. 12773

[9] Ekdahl AW, Andersson L, Friedrichsen M. "They do what they think is the best for me." Frail elderly patients' preferences for participation in their care during hospitalization. Patient Educ Couns. 2010; 80(2): 233-40. PMid:19945814 https ://doi.org/10.1016/j.pec. 20 09.10 .026
[10] Brown JP, Josse RG. Clinical practice guidelines for the diagnosis and management of osteoporosis in Canada. CMAJ. 2002; 167(10 Suppl): S1-34. PMid:12427685

[11] Bowling A. Mode of questionnaire administration can have serious effects on data quality. J Public Health (Oxf). 2005; 27(3): 281-91. PMid:15870099 https : //doi.org/10.1093/pubmed/fdi031

[12] Bæk-Jensen J. Ortopædkirurgiske patienters prioriteringer af og tilfredshed med sygehusvæsnets ydelser. Ph.d. afhandling, Det Sundhedsvidenskabelige Fakultet, Aarhus Universitet, [Århus]. 2004.

[13] Sitzia J. How valid and reliable are patient satisfaction data? An analysis of 195 studies. Int J Qual Health Care. 1999; 11(4): 319-28. PMid:10501602 https://doi.org/10.1093/intqhc/11.4.31 9

[14] Carr-Hill RA. The measurement of patient satisfaction. J Public Health Med. 1992; 14(3): 236-49. PMid:1419201

[15] Singh JA, et al. Preferred roles in treatment decision making among patients with cancer: a pooled analysis of studies using the Control Preferences Scale. Am J Manag Care. 2010; 16(9): 688-96. PMid:20873956

[16] Nørgaard B, et al. Patient-Experienced Quality in Five Emergency Departments in Denmark: A Multi-Centre Cross-Sectional Questionnaire Survey. J Clin Trials. 2013; 3: 147.

[17] Lau RL, et al. Patient satisfaction after total knee and hip arthroplasty. Clin Geriatr Med. 2012; 28(3): 349-65. PMid:22840303 https://doi.org/10.1016/j.cger.2012.05.001

[18] Chow A, et al. Patient-reported outcome measures: The importance of patient satisfaction in surgery. Surgery. 2009; 146(3): 435-443. PMid:19715800 https ://doi.org/10.1016/j.surg.2009.03 .019

[19] Liem IS, et al. Identifying a standard set of outcome parameters for the evaluation of orthogeriatric co-management for hip fractures. Injury. 2013; 44(11): 1403-12. PMid:23880377 https : //doi.org/ 10.1016/j.injury.2013.06.018

[20] Stevens M, et al. Patient satisfaction at and after discharge. Effect of a time lag. Patient Education and Counseling. 2006; 60(2): 241245. PMid:16253466 https ://doi.org/10.1016/j.pec. 2005 .01 .011 